\title{
Experimental and Theoretical Fuel Property Comparison of Four Different Waste Biomass with A Commercial Counterpart
}

\author{
Mustafa Kaan Baltacıoğlu ( $\nabla$ mkaan.baltacioglu@iste.edu.tr ) \\ Iskenderun Technical University https://orcid.org/0000-0002-4082-902X \\ Mustafa Tunahan Başar \\ Iskenderun Technical University: Iskenderun Teknik Universitesi \\ Hüseyin Turan Arat \\ Sinop University: Sinop Universitesi \\ Yasin Erdoğan \\ Maden Tetkik ve Arama Genel Mudurlugu
}

Research Article

Keywords: Pellet, alternative fuel, calorific value, organic waste management, thermal efficiency

Posted Date: November 10th, 2021

DOI: https://doi.org/10.21203/rs.3.rs-1023839/v1

License: (c) (7) This work is licensed under a Creative Commons Attribution 4.0 International License. Read Full License 


\section{Abstract}

This study focuses on determining the fuel properties of apple pulp, pomegranate seeds, pomegranate peel and orange peel wastes and converting them into pellet fuel. Within the scope of the study, the organic wastes were dried, ruined into small pieces and then pressed to take the pellet form. Moisture content, ash content, volatile matter determination, fixed carbon content, total sulfur content, hydrogen content, lower heating value and higher heating value were analyzed as solid fuel characterization process. Experiments were carried out in an internationally accredited laboratory in accordance with ASTM and TS EN ISO/IEC 17025 Standards. Considering the results, it was determined that the pellet obtained from fully dry state pomegranate seed had a calorific value of $4244 \mathrm{kcal} / \mathrm{kg}$, whereas the commercial pellet was $4759 \mathrm{kcal} / \mathrm{kg}$ under the same conditions. On the other hand, the moisture contents of the commercial pellet and pomegranate seed sample were $5.42 \%$ and $1.83 \%$, respectively. The drying process was one of the costliest stages of pellet production. The low moisture contents can reduce the production cost and shorten the time.

\section{Highlights}

- Fuel properties of considered wastes investigated for the first time.

- Analyses performed in an accredited laboratory.

- Relationship between the hydrogen contents and the heating values were nonlinear.

- The lowest HHV was seen in the orange peel.

- Pomegranate seeds provided the most promising LHV compared to commercial pellet.

\section{Introduction}

Alternative energy sources derived from biomass are the most common solution available and used commercially in both transportation and industry. Recently, the increase in the use of fossil based fuels due to the increasing energy demand enables scientists to focus on the development of biomass based fuels. Biofuels have become the key point of renewable and sustainable energy production as well as having effective results in reducing greenhouse gas emissions [1-4].

In the last half century, the continuous supply of energy from fossil fuels has caused a huge environmental pollution. This situation has become the main cause of global climate change problems [5-7]. All over the world, it focuses on improving environmental conditions and meeting energy needs in cleaner ways, and targets are set to slow down global warming [8-10]. In addition, it is seen that the trends towards renewable energy sources have increased in the last ten years. Accordingly, solid biofuel technologies such as pellets are expected to gain momentum $[11,12]$. However, it is stated that the search for new raw materials in pellet applications should be investigated [13]. In this context, solid fuels are considered as a type of fuel that is renewable and useful in research. [14]. Agricultural and forestry wastes, which can be described as organic wastes, generally create a great pollution when they are left to rot under free conditions and can significantly deteriorate environmental factors. However, it may be possible for these waste types to contribute to energy gains by using them in pellet production [15-17]. In addition, the idea of obtaining energy from agricultural wastes in order to solve environmental problems caused by organic wastes is the common opinion adopted in many studies [18]. Some difficulties that need to be solved in order to use biomass waste groups in energy production can be listed as not being able to form geometric shapes, preventing their decay in order to store, transport and make them functional [19-21]. Pelleting processes are one of the most suitable processes for solving these problems. If pelletizing is done, the density-based problems and the ability to shape can be applied on the raw material, making it easier to transport. However, pellets with increased energy efficiency can be obtained in desired sizes [22-25]. It is seen that the interest in pellet production has increased due to these advantages of pelleting in energy production from biomass. When a worldwide evaluation is made in pellet production, it is determined that there is almost a 50\% increase in production capacity between 2013 and 2018 [26, 27].

The sustainability of the raw material used in pelleting processes can be evaluated in terms of efficiency and in line with some parameters applied during production. Pellet quality depends on the moisture content of the biomass used, the amount of ash, particle size etc. While it varies depending on many parameters, the amount of pressure used in the production conditions of the pellet and temperature values are determinants [28, 29]. It is seen that woody structures used as raw materials in pellet production are generally waste materials remaining from wood-based structures [30]. In addition, it is thought that the primary raw material source of fuel particles produced from biomass is composed of vegetable waste [31]. In addition, large amounts of waste due to the consumption of many agricultural foods also occur, such as shell, pulp, seed. It is estimated that the wastes considered as urban waste will almost double by 2025 while it was 1.3 billion tons in $2010[32,33]$. However, alternative waste derivatives to pellet fuels, both as a mixture material and as a main raw material, are among the subjects that are continuously researched worldwide. Researches on the fact that organic wastes, especially in cellulosic structure, can produce effective results in pellet production are among the trend topics of recent times [34]. However, due to the increasing interest in using 
bio-waste-based materials as heat sources, researches on the adaptation of these waste groups to production processes are necessary [35]. In a study conducted on the transformation of waste masses generated in the fruit juice sector into energy by producing pellets, the wastes of organic products such as apples, carrots, beets were evaluated as an additive in pellet production, as a result, pure barley straw and apple, carrot beet wastes were added to the pellets in a mixture of $1 / 3$ It has been determined that the calorific value efficiency decreases compared to the state [36]. Within the scope of another study, it is mentioned that a plant specified as water hyacinth has harmful effects in environmental terms. At the same time, it is claimed that this plant can spread a lot in a short time. In the light of these precursors, it is thought that it may be beneficial to use water hyacinth plant in the pelleting process and use it in biofuel production [37]. Depending on the recovery of organic waste, it is accepted as the general purpose that the wastes are separated and treated as well as being able to be recycled. However, it is thought that obtaining energy and raw materials from organic wastes will bring great advantages in terms of environment and economy [38]. Bioenergy production is generally known for its low carbon emission in many countries of the world. However, in a study focusing on the production of electricity by using pellet energy in India, it is suggested that it is quite possible to provide employment and income economically and because of the high availability of pellet raw materials as bio waste [39]. In a study conducted in Canada's British Columbia province on the effects of using wood pellets instead of coal to produce clean electricity on cost analysis and environmental factors, for the region with sufficient technological level, if the wood pellets from forest waste constitute an alternative to coal, the carbon footprint is at $30 \%$ levels. It was determined that it could be reduced. On the contrary, the use of pellets cannot be obtained economically as cheaply as coal. Therefore, they suggest that various techniques and gains should be increased in pellet technology [40].

In this study, it has been tried to prove that among organic wastes, apple pulp, pomegranate seed, pomegranate peel and orange peel structures can be pelletized by firstly drying them to become raw materials from waste state and then giving them a shape. The fuel analysis of the experimental samples was obtained by using the ASTM D2013 method. The fuel properties of the commercial pellet and waste biomass were presented and discussed in detail. Furthermore, chemical contents and effects were investigated.

\section{Materials And Methods}

Four different sample types which apple pulp, pomegranate seed, pomegranate peel and orange peel, were selected as biomass samples to be evaluated within the scope of this study. First of all, water contents were eliminated to evaluate the waste mass. The bio waste samples were dried at $82^{\circ} \mathrm{C}$ for 4 hours. Experimental samples were transferred into the custom design cylindrical die (see Fig. 1.) to apply pressure. Dry and ruined samples were pelletized with the aid of a pressing bench (see Fig. 2.) with a capacity of 50 tons. This production technique was used only to test the retention of samples. The furnace was an air heated oven up to $300^{\circ} \mathrm{C}$ that can transfer heat to samples with the aid of a fan.

When full alignment between the upper jaw and the male clasp was achieved, it was gradually pressed on the sample. Pressure at levels of approximately 7.5 tons was gradually transmitted onto the 20-40 g samples for 1 hour. Standard pellet samples could be produced which have $28 \mathrm{~mm}$ diameter and maximum $30 \mathrm{~mm}$ length with the help of custom design cylindrical die.

As seen in Figure 3, pellet samples were successfully obtained at the end of the applied processes. It has been observed that the samples did not show a mechanical dissolution or a non-resistant behavior.

Evaluations were made depending on many parameters such as moisture ratios, calorific values, ash content, being able to be produced in standard sizes. However, the ratio of some amino acid structures in the raw material is among the determining factors in factors such as water content. Additionally, raw material particle size distributions have a very important place for pellet quality [41-43].

Table 1 presents the mass and volumetric information of the pellet samples. The bulk density $(\rho b)$ and pellet density ( $\rho p)$ were obtained based on the volumes of the pellets before and after the pressing.

\subsection{Physical Characterization of Pellets}

For physical characterization applications, first, the bulk densities of pellets were calculated and secondly, after obtaining pellet densities, the porosity amount expressing the compressibility ratio was found according to the formula given in Eq. 1 Within the scope of the study, these density values were obtained depending on the volume changes due to the fixed mass obtained by using precision scales [44].

$\varepsilon_{0}(-)=1-\frac{\rho b}{\rho p}$

In this subsection Eq. 2 is presented to calculate the theoretical higher heating values of the samples which are depending on the fixed carbon amounts (FC), the amount of volatile matter (VM) and the amount of ash (A) $[44,45]$. This process was carried out to compare the actual analysis results with the theoretically obtained results and presented in the next section.

Page 3/15 
Table 1

Mass and volumetric dimensions of pellets produced

\begin{tabular}{|c|c|c|c|c|}
\hline \multirow{2}{*}{$\begin{array}{l}\text { Sample type } \\
\text { Apple pulp }\end{array}$} & \multirow{2}{*}{$\begin{array}{l}\text { Mass of sample (g) } \\
28.6\end{array}$} & \multicolumn{2}{|c|}{ Shape of sample } & \multirow{2}{*}{$\begin{array}{l}\text { Pellet } \\
\text { Density }\left(\mathrm{kg} / \mathrm{dm}^{3}\right) \rho p \\
1.45147685\end{array}$} \\
\hline & & \multirow[t]{5}{*}{$\mathrm{r}=14 \mathrm{~mm}$} & $\mathrm{~L}=32 \mathrm{~mm}$ & \\
\hline Pomegranate seed & 23.8 & & $\mathrm{~L}=33 \mathrm{~mm}$ & 1.17127016 \\
\hline Pomegranate peel & 23.8 & & $\mathrm{~L}=30 \mathrm{~mm}$ & 1.288397214 \\
\hline Orange peel & 31.4 & & $\mathrm{~L}=34 \mathrm{~mm}$ & 1.499839532 \\
\hline Commercial pellet & 30.1 & & $\mathrm{~L}=35 \mathrm{~mm}$ & 1.396665866 \\
\hline Sample type & Mass of sample (g) & \multicolumn{2}{|c|}{ Shape of mold } & Sample Density $\left(\mathrm{kg} / \mathrm{dm}^{3}\right) \rho b$ \\
\hline Apple pulp & 28.6 & \multirow[t]{5}{*}{$\mathrm{r}=14 \mathrm{~mm}$} & \multirow[t]{5}{*}{$\mathrm{L}=75 \mathrm{~mm}$} & 0.619296785 \\
\hline Pomegranate seed & 23.8 & & & 0.515358863 \\
\hline Pomegranate peel & 23.8 & & & 0.515358863 \\
\hline Orange peel & 31.4 & & & 0.67992724 \\
\hline Commercial pellet & 30.1 & & & 0.651777386 \\
\hline
\end{tabular}

Experiments were carried out in the accredited laboratories of the General Directorate of Mineral Research and Exploration. Results were obtained in accordance with related standards. LECO brand TGA 701 model Thermogravimetric device was used for moisture, ash and volatile matter analysis; ELTRA brand CS 580 Device was used for sulfur and carbon analysis; IKA brand C 6000 calorimeter device was used for lower and higher heating value analysis while LECO brand CHN628 Elementary Analyzer was used for hydrogen content determination. The measurement standards of the devices are presented with the results in the next section. In the next section, the fuel analysis results of the test samples and the commercial pellet will be presented in comparison with graphs and tables.

\section{Results}

Within the scope of this study, it was determined that apple, orange and pomegranate fruit could be transformed into pellet form after dehumidification, milling and pressing processes in order to utilize their wastes. Test samples were quite rigid and their strength analysis were done but did not consider in the scope of this research. When the strength comparison of commercial pellets and test samples was made, samples obtained from wastes gave more durable results.

Table 2

The compressibility ratio of pellets

\begin{tabular}{|c|c|}
\hline Sample type & $\varepsilon_{0}(-)$ \\
\hline Apple pulp & 0.574 \\
\hline Pomegranate seed & 0.560 \\
\hline Pomegranate peel & 0.600 \\
\hline Orange peel & 0.547 \\
\hline Commercial pellet & 0.533 \\
\hline
\end{tabular}

Eq. 1 and the measurement results in Table 2 were used to calculate bulk densities of test samples which are presented in Table 2. Bulk density and the porosity value affect the burning time, emission values after combustion and heat-based conversion events [46]. Relatively best porosity value was obtained from pomegranate peel among the organic wastes. However, similar results were seen in other wastes and commercial pellets. Remarkably, all considered wastes provide better mechanical pelletizability than commercial pellets due to compressibility. In this context, it is known that cellulosic structures add improvements to the binding effects and mechanical effects [47]. On the other hand, it is mentioned that the pellet particle density of woody structures should be at or above the limit value of $600 \mathrm{~kg} / \mathrm{m} 3$ 
[48]. In this case, it is seen that the pellet density of all samples were almost twice this threshold value. In this case, it is believed that the pellets obtained can be mechanically effective in normal pelletizing processes.

Considering the bulk density of organic waste samples evaluated within the scope of the study, for apple pulp; $619.296785 \mathrm{~kg} / \mathrm{m} 3$ for pomegranate seed; $515.358863 \mathrm{~kg} / \mathrm{m}^{3}$ for pomegranate peel; $515.358863 \mathrm{~kg} / \mathrm{m}^{3}$ for orange peel; $679.92724 \mathrm{~kg} / \mathrm{m}^{3}$ for commercial pellet; It was found to be $651.777386 \mathrm{~kg} / \mathrm{m}^{3}$. Similarly, in a study conducted by Acda, M.N in woody structures, the bulk densities of pellets obtained from tropical hardwoods using woody structures such as Gmelina arborea, Acacia mangium and Paraserianthes falcataria were $621.24 \mathrm{~kg} / \mathrm{m}^{3}, 732.45 \mathrm{~kg} / \mathrm{m}^{3}, 687.23 \mathrm{~kg} / \mathrm{m}^{3}$, respectively [49]. It can be said that the orange peel had a resemblance to woody structures in terms of bulk densities than other organic wastes of this research.

Table 3

Chemical contents and fuel properties (Original: O, Dry: D)

\begin{tabular}{|c|c|c|c|c|c|c|c|c|c|c|c|c|}
\hline & \multicolumn{2}{|c|}{$\begin{array}{l}\text { Commercial } \\
\text { pellet }\end{array}$} & \multicolumn{2}{|c|}{ Apple pulp } & \multicolumn{2}{|c|}{$\begin{array}{l}\text { Pomegranate } \\
\text { peel }\end{array}$} & \multicolumn{2}{|c|}{$\begin{array}{l}\text { Pomegranate } \\
\text { seed }\end{array}$} & \multicolumn{2}{|c|}{ Orange peel } & \multirow[t]{2}{*}{$\begin{array}{l}\text { Measuring } \\
\text { Devices }\end{array}$} & \multirow[t]{2}{*}{ Standards } \\
\hline & 0 & D & 0 & D & 0 & D & 0 & D & 0 & D & & \\
\hline $\begin{array}{l}\text { Moisture } \\
\text { Content (\%) }\end{array}$ & 5.42 & - & 4.74 & - & 9.17 & - & 1.83 & - & 4.23 & - & $\begin{array}{l}\text { LECO - } \\
\text { TGA } 701\end{array}$ & $\begin{array}{l}\text { ASTM E914, } \\
\text { ASTME1131, } \\
\text { ASTM E } 18 \\
68, \text { DIN } 51 \\
006, \text { ISO } 71 \\
\text { 11, ISO } 113 \\
58\end{array}$ \\
\hline $\begin{array}{l}\text { Ash Content } \\
(\%)\end{array}$ & 1.02 & 1.08 & 2.58 & 2.71 & 3.75 & 4.13 & 3.88 & 3.96 & 3.46 & 3.62 & $\begin{array}{l}\text { LECO - } \\
\text { TGA } 701\end{array}$ & $\begin{array}{l}\text { ASTM E914, } \\
\text { ASTME1131, } \\
\text { ASTM E } 18 \\
68, \text { DIN } 51 \\
006 \text {, ISO } 71 \\
\text { 11, ISO } 113 \\
58\end{array}$ \\
\hline $\begin{array}{l}\text { Volatile Matter } \\
(\%)\end{array}$ & 79.25 & 83.79 & 75.88 & 79.65 & 64.24 & 70.73 & 77.91 & 79.35 & 75.80 & 79.15 & $\begin{array}{l}\text { LECO - } \\
\text { TGA } 701\end{array}$ & $\begin{array}{l}\text { ASTM E914, } \\
\text { ASTME1131, } \\
\text { ASTM E } 18 \\
68 \text {,DIN } 51 \\
006 \text {, ISO } 71 \\
\text { 11, ISO } 113 \\
58\end{array}$ \\
\hline $\begin{array}{l}\text { Fixed Carbon } \\
(\%)\end{array}$ & 14.32 & 15.13 & 16.80 & 17.64 & 22.84 & 25.15 & 16.39 & 16.69 & 16.51 & 17.24 & $\begin{array}{l}\text { ELTRA - } \\
\text { CS } 580\end{array}$ & $\begin{array}{l}\text { ASTM D } \\
4239, \text { DIN } \\
\text { EN } 13137\end{array}$ \\
\hline $\begin{array}{l}\text { Total Sulfur } \\
\text { (S) (\%) }\end{array}$ & 0.02 & 0.03 & 0.05 & 0.05 & 0.06 & 0.06 & 0.26 & 0.26 & 0.14 & 0.14 & $\begin{array}{l}\text { ELTRA - } \\
\text { CS } 580\end{array}$ & $\begin{array}{l}\text { ASTM D } \\
4239, \text { DIN } \\
\text { EN } 13137\end{array}$ \\
\hline $\begin{array}{l}\text { Lower Heating } \\
\text { Value(kcal/kg) }\end{array}$ & 4470 & 4759 & 3604 & 3812 & 3594 & 4016 & 4156 & 4244 & 3445 & 3623 & $\begin{array}{l}\text { IKA - C } \\
6000\end{array}$ & $\begin{array}{l}\text { DIN 51900, } \\
\text { ISO 1928, } \\
\text { ASTM 5468, } \\
\text { ASTM } 5865\end{array}$ \\
\hline $\begin{array}{l}\text { Higher } \\
\text { Heating } \\
\text { Value(kcal/kg) }\end{array}$ & 4792 & 5066 & 3940 & 4135 & 3871 & 4262 & 4506 & 4589 & 3755 & 3921 & $\begin{array}{l}\text { IKA-C } \\
6000\end{array}$ & $\begin{array}{l}\text { DIN } 51900, \\
\text { ISO 1928, } \\
\text { ASTM 5468, } \\
\text { ASTM } 5865\end{array}$ \\
\hline $\begin{array}{l}\text { Hydrogen } \\
\text { Content (\%) }\end{array}$ & 5.57 & 5.89 & 5.91 & 6.20 & 4.29 & 4.72 & 6.51 & 6.63 & 5.47 & 5.71 & $\begin{array}{l}\text { LECO - } \\
\text { CHN } 628\end{array}$ & ASTM, ISO \\
\hline
\end{tabular}

Fuel characterization data obtained from the analysis are shown in Table 3 The chemical contents of the pellets and organic structures were included. In terms of moisture content, it is noteworthy that the driest sample structure is pomegranate seed and it is approximately 3 times drier than commercial pellets. The low water content here means that the amount of energy consumed for drying the raw material during pelletizing will be lower. On the other hand, it is reported that drying cost is considered the biggest expense in pellet processes [50].

Organic wastes had lower moisture content than commercial pellet except for pomegranate peel. In line with these data, the inclusion of organic wastes in pellet applications may bring convenience during production. The hydrogen contents of the samples are also given in Table 3. It is seen here that there are similarities in the amount of hydrogen content of the test samples. Despite this similarity, it is also a 
striking factor that there is no linear or opposite ratio between hydrogen content and heating values. In a related study, it is mentioned that the hydrogen content or amount does not have much effect on pellet fuel [51]. However, in different studies on this point, it is also reported that the fixed carbon amount and hydrogen value are the factors that directly affect the calorific values of the samples. An increment of hydrogen ratio is thought to produce advantageous for fuel quality [52-54]. In this context, it is seen that the pomegranate seed and apple pulp wastes contain more hydrogen than the commercial pellet on average $14.6 \%$ and $5.6 \%$, respectively. More particular investigations are needed in this respect, it is necessary to investigate the effects of hydrogen content in pellet applications.

Table 4

Pellet Standards [55-56]

\begin{tabular}{|llllllll|}
\hline Parameter & Unit & \multicolumn{2}{l}{ ISO 17225-2 } & & Ö-Norm & DIN & DIN \\
\cline { 2 - 6 } & & Class 1 & Class2 & Class3 & M7135 & 51731 & Plus \\
\hline Diameter & $\mathrm{mm}$ & $\leq 25$ & $\leq 25$ & $\leq 25$ & $4-10$ & $4-10$ & $4-10$ \\
\hline Length & $\mathrm{mm}$ & $\leq 4 \times \mathrm{d}$ & $\leq 5 \times \mathrm{d}$ & $\leq 6 \times \mathrm{d}$ & $\leq 5 \times \mathrm{d}$ & $\leq 50$ & $\leq 5 \times \mathrm{d}$ \\
\hline Density & $\mathrm{kg} / \mathrm{dm}^{3}$ & $\geq 0.6$ & $\geq 0.5$ & $\geq 0.5$ & $>1,12$ & $1,0-1,4$ & $>1,12$ \\
\hline Moisture Content & $\%$ & $\leq 10$ & $\leq 10$ & $\leq 12$ & $\leq 10$ & $\leq 12$ & $\leq 10$ \\
\hline Ash content & $\%$ & $\leq 0.7$ & $\leq 1.5$ & $<1.5$ & $\leq 0.5$ & $\leq 1.5$ & $\leq 0.5$ \\
\hline Calorific value & $\mathrm{kcal} / \mathrm{kg}$ & $\geq 3955.2$ & & & $\geq 4299.2$ & $3702.1-4657.4$ & $\geq 4299.2$ \\
\hline Sulphur content & $\%$ & $\leq 0.08$ & $\leq 0.08$ & - & $\leq 0.04$ & $\leq 0.08$ & $\leq 0.04$ \\
\hline
\end{tabular}

From the view of dimensional comparison of the pellets produced in this study with the standards, test samples were obtained with the aid of a custom die. Test samples were produced with slightly larger diameters than the common pellet size. Diameter and length were $28 \mathrm{~mm}$ and 30-35 mm, respectively. In terms of length, pellets were in accordance with all standards but in terms of diameter ISO $17225-2$ standards have been approached up to a certain point (Table 4). On the other hand, it is seen that the produced pellets were within acceptable limits for all standards (Table 1) in terms of density. It can be seen that the same conditions are provided for the moisture content. In this context, considering that the emission effects worsen with the increase in moisture content [57], it is promising that the samples being within the limits of the standards. When the data obtained in terms of ash content are compared with the standards, it is seen that only commercial pellets comply with ISO 17225-2 second class pellet standard, third class pellet group and DIN 51731 standards. However, it has been determined that the ash content of pellets obtained from apple, pomegranate and orange wastes are not within acceptable limits. The low ash content, which has an important place in pellet quality in pellet applications, is often the desired factor [5860]. It is desired to have a low ash ratio for many important factors such as high thermal efficiency [61], ensuring more environmentally friendly and cleaner fuel production [62-64], easier thermochemical and biochemical transformations [65-67]. Matúš, M. et al. conducted a study on wheat straw. High ash formations were reported in the preliminary analysis of wheat straw [47]. Considering organic waste, it is an expected output to have high ash rates in the wastes of apple, orange and pomegranate fruits according to the commercial pellet. Considering the amount of sulfur, it is seen that the commercial pellet complies with all standards. However, it is seen that apple pulp and pomegranate peel wastes comply with ISO 17225-2 and DIN 51731 standards. Nevertheless, orange peel and pomegranate seed waste could not be in any standard range in terms of sulfur content. 
Table 5

LHV and HHV comparison of experimental samples

\begin{tabular}{|llll|}
\hline Dry Sample type & Lower Heating Value (kcal/kg) & Percentage change & Result \\
\hline Commercial pellet & 4759 & $\% 100$ & $\% 0$ \\
\hline Pomegranate peel & 4016 & $\% 84.3$ & $-\% 15.7$ \\
\hline Pomegranate seed & 4244 & $\% 89$ & $-\% 11$ \\
\hline Orange peel & 3623 & $\% 76$ & $-\% 24$ \\
\hline Apple pulp & 3812 & $\% 80$ & $-\% 20$ \\
\hline Commercial pellet & 5066 & Percentage change & Result \\
\hline Pomegranate peel & 4262 & $\% 100$ & $\% 0$ \\
\hline Pomegranate seed & 4589 & $\% 84.1$ & $-\% 15.9$ \\
\hline Orange peel & 3921 & $\% 90.5$ & $-\% 9.5$ \\
\hline Apple pulp & 4135 & $\% 77.3$ & $-\% 22.7$ \\
\hline
\end{tabular}

Table 5 shows the lower and higher heating values of the dry samples. Variations are determined by comparing with The commercial pellet results as the base point. Changes in the thermal values of pellets obtained from organic wastes were interpreted according to commercial pellets and analyzed. From the view of LHV, there was a thermal loss of $20 \%$ in apple pulp, $11 \%$ in pomegranate seed, $15 \%$ in pomegranate peel and $24 \%$ in orange peel compared to commercial pellet. Likewise, there was a thermal loss of $18 \%$ for apple pulp, $9.5 \%$ in pomegranate seed, $15.9 \%$ in pomegranate peel and $22 \%$ in orange peel on HHV. In general, fewer thermal losses occur when combustion occurs with full efficiency. However, considering waste recovery and reuse, organic waste-based pellet applications offer advantages despite these thermal losses. Leaving aside the comparison to commercial pellets to examine according to fuel standards, all organic wastes except the orange peel were found to be in the appropriate range from the view of ISO 17225-2 standards. In addition, it has been determined that pomegranate seeds and commercial pellets comply with Ö-Norm M7135 and DIN Plus standards. Finally, it is seen that all samples obtained from organic wastes comply with DIN 51731 standards.

Table 6

Theoretical calorific value calculations

\begin{tabular}{|lcccc|}
\hline Sample type & \multicolumn{2}{c|}{ Original Sample type } & \multicolumn{2}{c|}{ Dry Sample type } \\
\hline Theoretical Heating Value & $\mathrm{MJ} / \mathrm{kg}$ & $\mathrm{kcal} / \mathrm{kg}$ & $\mathrm{MJ} / \mathrm{kg}$ & $\mathrm{kcal} / \mathrm{kg}$ \\
\hline Commercial pellet & 17.41 & 4158.3 & 18.4 & 4394.7 \\
\hline Pomegranate peel & 18.06 & 4313.5 & 19.88 & 4748.2 \\
\hline Pomegranate seed & 17.91 & 4277.7 & 18.24 & 4356.5 \\
\hline Orange peel & 17.62 & 4208.4 & 18.4 & 4394.7 \\
\hline Apple pulp & 17.75 & 4239.5 & 18.63 & 4449.6 \\
\hline
\end{tabular}

The theoretical heating value results are given in Table 6 were calculated by using Eq. 2. Measured fixed carbon, ash content and volatile matter were the factors that affect the outcome. According to experimental data, commercial pellet provided the best calorific value result while pomegranate peel sample was the best for theoretical calculations. Another remarkable point was that all samples complied with standards according to theoretical calorific value calculations.

Figure 4 presents the experimental and theoretical LHV analysis of the samples for dry and original forms. According to the data obtained from organic wastes, it is seen that the LHV increases from the experimental result of the original form to the theoretical results of the dry form. The same situation is not seen in commercial pellets. In addition, while the calorific values obtained in the theoretical calculations for all waste samples were higher while this situation occurred in the opposite way for the commercial pellet. Among all waste samples, the pomegranate seeds sample performed the most similar experimental and theoretical results.

Figure 5. presents the experimental and theoretical HHV analysis of the samples for dry and original forms. Results and characteristics of graphs are similar to LHV results except for the pomegranate seed sample (Fig. 5.). In addition, the sample in which all calorific value results are closest to each other was pomegranate seed. A notable point of Fig. 5. was, unlike other samples, in pomegranate seeds and

Page $7 / 15$ 
commercial pellets, the calorific value results obtained in the experimental results were higher than theoretical calculations. In general, the occurrence of these differences between experimental results and theoretical calculations in the calorific value parameter might be hydrogen amounts or other parameters that not taken into account. In this context, it is thought that elements such as nitrogen, oxygen, ash content and hydrogen might have an effect on the calorific value [24].

According to both theoretical calculation and experimental measurement results, it has been determined that there is a relationship between the moisture content of the samples and their calorific values. The percentage increase in the calorific values of the samples is almost equal to the moisture content removed by the applied drying process.

Numerically; the moisture content of commercial pellet, apple pulp, pomegranate peel, pomegranate seed and orange peel are $5.42 \%$, $4.74 \%$, $9.17 \%, 1.83 \%$ and $4.23 \%$, respectively. Theoretical LHV increase rates of these samples in their dry form are $5.68 \%, 4.96 \%, 10.07 \%, 1.84 \%$ and $4.42 \%$, respectively. When these increments are examined for LHV values based on experimental analysis, it is $6.46 \%, 5.77 \%, 11.75 \%$, $2.11 \%$ and $5.16 \%$ for commercial pellets, apple pomace, pomegranate peel, pomegranate seeds and orange peel, respectively. The positive variation of HHV with the moisture content removal is higher than LHV. However, it is important to have the optimum value for the amount of moisture. It is stated that the energy spent for compaction in pellet production increases as the moisture content decreases [68]. In this context, optimum moisture content affects both the calorific value and the energy consumed in pellet production.

In addition, it was determined that the number of volatile substances increased with the dryness value of the samples which positively affects the calorific value. A 3-7\% volatile matter variation was observed between the dry and original forms of the test samples. It is thought that this situation affects calorific value calculations. Wichianphong, $\mathrm{N}$ et al., in their study on the pelletization of water hyacinth and coffee waste, reported that the maximum calorific value of 4,275,341 cal/ $\mathrm{kg}$ could be obtained in the pellet sample with $5.61 \%$ moisture, $73.20 \%$ volatile matter, $10.11 \%$ fixed carbon content [69]. An evaluation can be made about pellet quality by considering the volatile matter number and moisture content.

As the last, there is fixed carbon amount difference between the original and dry samples at a range of $0.3 \%$ and $0.84 \%$. This difference creates an effective difference in calorific value calculations. It is also reported that the amount of fixed carbon is among the factors that increase the calorific value [70, 71].

\section{Discussion}

Considering the general studies, the evaluation of these waste types in pellet applications for the first time is the innovative aspect of the study. Looking at the main data obtained, it is seen that the hydrogen content alone does not have a direct effect. However, when evaluated together with other data results, it is thought that hydrogen makes a great contribution to fuel quality.

Although the results of the commercial pellet in terms of emission are better than the results of organic waste, the fact that organic wastes contain more moisture in terms of moisture content provides a great economic advantage in production conditions. In addition, the fact that the waste group that is desired to be evaluated as organic has no value, creates economically important advantages compared to commercial pellets.

Keeping the moisture content of the samples at a certain optimum value has a very sensitive place in pellet applications. While the high moisture content obtained within the scope of the study reduces the cost during production, excessive moisture content negatively affects the calorific value as seen in the pomegranate peel. Pellet fuel is considered a more environmentally friendly fuel compared to coal and similar fuel types. In this study, it is proved both experimentally and theoretically that pellet fuels that can be obtained from organic wastes can provide this, both economically and environmentally.

As a general opinion, it will be possible to obtain a quality fuel if a mixture of other waste types with better emission results is obtained by using the pomegranate seed, which has high efficiency in terms of calorific value, as the dominant component, instead of evaluating the organic wastes separately in pure form.

\section{Conclusion}

Within the scope of this study, it has been clearly proven that organic wastes such as apple pulp, pomegranate seeds, pomegranate peel and orange peel can be preferred for pellet applications. Alternative solutions were investigated in deep from the view of benefits and efficiencies. Considered organic household waste in this study would offer a new solution to local energy demand in an environmentally friendly way. 
Although pellets obtained from organic wastes show some thermal loss compared to commercial pellets, it is an important output that their mechanical producibility is easier. In addition, their compliance with international standards allows them to be used in a mixture. One of the most important factors in terms of the chemical contents of the samples is that the hydrogen contents are higher in the organic wastes.

This issue needs to be investigated separately.

One of the most important factors in terms of the chemical contents of the samples is that the hydrogen contents are higher in the organic wastes. This issue needs to be investigated separately. Considering the compliance of the samples with the standards, it is seen that they exhibit behaviors that do not comply with the standards in terms of ash content. In addition, considering the fixed carbon amount, it is seen that they have higher carbon content than commercial pellets. One of the solutions for this issue might be dual or multi biomass feedstock combinations as a pellet. At this point, it was concluded that pellets obtained from considered organic wastes should be improved in terms of environmental conditions.

As a result, considering that the organic wastes within the scope of this study have no monetary value, it is clearly seen that they can be evaluated in pellet applications. It can be concluded that using them as additives to wood-based biomass is the best possible solution.

Finally, a new approach suggested for alternative energy sources by using apple pulp, pomegranate seeds, pomegranate peel and orange peel in renewable energy studies. Results showed that these organic wastes are candidates to take a role in the energy market.

\section{Declarations}

\section{Acknowledgments}

The authors acknowledge to Mineral Research and Exploration General Directorate, MAT Department Laboratory for fuel analysis.

\section{Declaration of competing interest and Availability of Data}

The authors declare that they have no known competing financial interests or personal relationships that could have appeared to influence the work reported in this paper. Additionally, authors have agreed that datasets and experimental samples can be obtained from the corresponding author on reasonable request.

\section{References}

1. Sultana A, Kumar A, Harfield D (2010) Development of agri-pellet production cost and optimum size. Bioresour Technol 101(14):56095621

2. Fusi A, Bacenetti J, Proto AR, Tedesco DE, Pessina D, Facchinetti D (2021) Pellet Production from Miscanthus: Energy and Environmental Assessment. Energies 14(1):73

3. Lisý M, Lisá H, Jecha D, Baláš M, Križan P (2020) Characteristic properties of alternative biomass fuels. Energies 13(6):1448

4. Ríos-Badrán IM, Luzardo-Ocampo I, García-Trejo JF, Santos-Cruz J, Gutiérrez-Antonio C (2020) Production and characterization of fuel pellets from rice husk and wheat straw. Renewable Energy 145:500-507

5. Höök M, Tang X (2013) Depletion of fossil fuels and anthropogenic climate change-A review. Energy policy 52:797-809

6. Jiang X, Guan D (2016) Determinants of global CO2 emissions growth. Appl Energy 184:1132-1141

7. Raupach MR, Marland G, Ciais P, Le Quéré C, Canadell JG, Klepper G, Field CB (2007) Global and regional drivers of accelerating CO2 emissions. Proceedings of the National Academy of Sciences, 104(24), 10288-10293

8. Anselmo Filho P, Badr O (2004) Biomass resources for energy in North-Eastern Brazil. Appl Energy 77(1):51-67

9. Dhillon RS, von Wuehlisch G (2013) Mitigation of global warming through renewable biomass. Biomass Bioenergy 48:75-89

10. Benoist A, Dron D, Zoughaib A (2012) Origins of the debate on the life-cycle greenhouse gas emissions and energy consumption of firstgeneration biofuels-A sensitivity analysis approach. Biomass Bioenergy 40:133-142

11. Lyytimäki J (2018) Renewable energy in the news: Environmental, economic, policy and technology discussion of biogas. Sustainable Production and Consumption 15:65-73

12. Negri M, Bacenetti J, Manfredini A, Lovarelli D, Fiala M, Maggiore TM, Bocchi S (2014) Evaluation of methane production from maize silage by harvest of different plant portions. Biomass Bioenergy 67:339-346

13. Setter C, Borges FA, Cardoso CR, Mendes RF, Oliveira TJP (2020) Energy quality of pellets produced from coffee residue: Characterization of the products obtained via slow pyrolysis. Ind Crops Prod 154:112731 
14. Atay OA, Ekinci K (2020) Characterization of pellets made from rose oil processing solid wastes/coal powder/pine bark. Renewable Energy 149:933-939

15. Kumar A, Cameron JB, Flynn PC (2003) Biomass power cost and optimum plant size in western Canada. Biomass Bioenergy 24(6):445-464

16. Nizamuddin S, Mubarak NM, Tiripathi M, Jayakumar NS, Sahu JN, Ganesan P (2016) Chemical, dielectric and structural characterization of optimized hydrochar produced from hydrothermal carbonization of palm shell. Fuel 163:88-97

17. Toscano G, Riva G, Pedretti EF, Corinaldesi F, Mengarelli C, Duca D (2013) Investigation on wood pellet quality and relationship between ash content and the most important chemical elements. Biomass Bioenergy 56:317-322

18. Wang Z, Zhai Y, Wang T, Wang B, Peng C, Li C (2020) Pelletizing of hydrochar biofuels with organic binders. Fuel 280:118659

19. Verma VK, Bram S, De Ruyck J (2009) Small scale biomass heating systems: standards, quality labelling and market driving factorsan EU outlook. Biomass Bioenergy 33(10):1393-1402

20. Kaliyan N, Morey RV (2009) Factors affecting strength and durability of densified biomass products. Biomass Bioenergy 33(3):337359

21. Nunes LJR, Matias JCO, Catalão JPS (2014) Mixed biomass pellets for thermal energy production: A review of combustion models. Appl Energy 127:135-140

22. Sánchez J, Curt MD, Sanz M, Fernández J (2015) A proposal for pellet production from residual woody biomass in the island of Majorca (Spain). AIMS Energy 3(3):480-504

23. Whittaker C, Shield I (2017) Factors affecting wood, energy grass and straw pellet durability-A review. Renew Sustain Energy Rev 71:111

24. Obernberger I, Thek G (2010) The pellet handbook: the production and thermal utilisation of pellets. Routledge

25. Larsson SH, Agar DA, Rudolfsson M, da Silva Perez D, Campargue M, Kalén G, Thyrel M (2021) Using the macromolecular composition to predict process settings that give high pellet durability in ring-die biomass pellet production. Fuel 283:119267

26. Calderón C, Gauthier G, Jossart JM (2019) Bioenergy Europe Statistical Report 2019-Key Findings. European Association Bioenergy Europe: Brussels, Belgium

27. Picchio R, Latterini F, Venanzi R, Stefanoni W, Suardi A, Tocci D, Pari L (2020) Pellet production from woody and non-woody feedstocks: A review on biomass quality evaluation. Energies 13(11):2937

28. Samuelsson R, Thyrel M, Sjöström M, Lestander TA (2009) Effect of biomaterial characteristics on pelletizing properties and biofuel pellet quality. Fuel Process Technol 90(9):1129-1134

29. Larsson SH, Thyrel M, Geladi P, Lestander TA (2008) High quality biofuel pellet production from pre-compacted low density raw materials. Bioresour Technol 99(15):7176-7182

30. Hoefnagels R, Junginger M, Faaij A (2014) The economic potential of wood pellet production from alternative, low-value wood sources in the southeast of the US. Biomass Bioenergy 71:443-454

31. Vorotinskienė L, Paulauskas R, Zakarauskas K, Navakas R, Skvorčinskienè R, Striūgas N (2020) Parameters influencing wet biofuel drying during combustion in grate furnaces. Fuel 265:117013

32. Pavi S, Kramer LE, Gomes LP, Miranda LAS (2017) Biogas production from co-digestion of organic fraction of municipal solid waste and fruit and vegetable waste. Bioresour Technol 228:362-367

33. Hoornweg D, Bhada-Tata P (2012) What a waste: a global review of solid waste management

34. Zawiślak K, Sobczak P, Kraszkiewicz A, Niedziółka I, Parafiniuk S, Kuna-Broniowska I, Obidziński S (2020) The use of lignocellulosic waste in the production of pellets for energy purposes. Renewable Energy 145:997-1003

35. Chen H, Forbes EGA, Archer J, De Priall O, Allen M, Johnston C, Rooney D (2019) Production and characterization of granules from agricultural wastes and comparison of combustion and emission results with wood based fuels. Fuel 256:115897

36. Chojnacki J, Zdanowicz A, Ondruška J, Šooš L', Smuga-Kogut M (2021) The Influence of Apple, Carrot and Red Beet Pomace Content on the Properties of Pellet from Barley Straw. Energies 14(2):405

37. Hudakorn T, Sritrakul N (2020) Biogas and biomass pellet production from water hyacinth. Energy Reports 6:532-538

38. Polprasert C (2007) Organic waste recycling: technology and management. IWA publishing

39. Purohit P, Chaturvedi V (2018) Biomass pellets for power generation in India: a techno-economic evaluation. Environ Sci Pollut Res 25(29):29614-29632

40. Yun H, Clift R, Bi X (2020) Environmental and economic assessment of torrefied wood pellets from British Columbia. Energy Conv Manag 208:1125138

Page $10 / 15$ 
41. Behnke KC (1994, March) Factors affecting pellet quality. Maryland Nutrition Conference. Dept of Poultry Science and animal Science, collage of Agricultural, University of Maryland, collage Park

42. Turner $\mathrm{R}$ (1995) Bottomline in feed processing: achieving optimum pellet quality. Feed Management 46(12):30-33

43. Thomas M, Van Zuilichem DJ, Van der Poel AFB (1997) Physical quality of pelleted animal feed. 2. Contribution of processes and its conditions. Anim Feed Sci Technol 64(2-4):173-192

44. Moliner C, Lagazzo A, Bosio B, Botter R, Arato E (2020) Production, Characterization, and Evaluation of Pellets from Rice Harvest Residues. Energies 13(2):479

45. Parikh J, Channiwala SA, Ghosal GK (2005) A correlation for calculating HHV from proximate analysis of solid fuels. Fuel 84(5):487494

46. Igathinathane C, Tumuluru JS, Sokhansanj S, Bi X, Lim CJ, Melin S, Mohammad E (2010) Simple and inexpensive method of wood pellets macro-porosity measurement. Bioresour Technol 101(16):6528-6537

47. Matúš M, Križan P, Šooš L', Beniak J (2018) The effect of papermaking sludge as an additive to biomass pellets on the final quality of the fuel. Fuel 219:196-204

48. ISO E (2014) Solid biofuels-fuel specifications and classes-Part 1: general requirements

49. Acda MN (2015) Physico-chemical properties of wood pellets from coppice of short rotation tropical hardwoods. Fuel 160:531-533

50. Uasuf A, Becker G (2011) Wood pellets production costs and energy consumption under different framework conditions in Northeast Argentina. Biomass Bioenergy 35(3):1357-1366

51. Telmo C, Lousada J, Moreira N (2010) Proximate analysis, backwards stepwise regression between gross calorific value, ultimate and chemical analysis of wood. Bioresour Technol 101(11):3808-3815

52. Vassilev SV, Baxter D, Andersen LK, Vassileva CG, Morgan TJ (2012) An overview of the organic and inorganic phase composition of biomass. Fuel 94:1-33

53. Baxter LL (1993) Ash deposition during biomass and coal combustion: a mechanistic approach. Biomass Bioenergy 4(2):85-102

54. Lynch D, Henihan AM, Bowen B, Lynch D, McDonnell K, Kwapinski W, Leahy JJ (2013) Utilisation of poultry litter as an energy feedstock. Biomass Bioenergy 49:197-204

55. Fiedler F (2004) The state of the art of small-scale pellet-based heating systems and relevant regulations in Sweden, Austria and Germany. Renewable and sustainable energy reviews, 8(3), 201-221

56. Sungur B, Topaloğlu B, Özbey M (2018) Pelet Yakıtlı Yakma Sistemlerinin Isıl Performans ve Emisyon Açısından İncelenmesi. Mühendis ve Makina 59(693):64-84

57. Price-Allison A, Lea-Langton AR, Mitchell EJS, Gudka B, Jones JM, Mason PE, Williams A (2019) Emissions performance of high moisture wood fuels burned in a residential stove. Fuel 239:1038-1045

58. Vassilev SV, Vassileva CG, Vassilev VS (2015) Advantages and disadvantages of composition and properties of biomass in comparison with coal: An overview. Fuel 158:330-350

59. Demirbas A (2005) Potential applications of renewable energy sources, biomass combustion problems in boiler power systems and combustion related environmental issues. Prog Energy Combust Sci 31(2):171-192

60. Bilandzija N (2012) Energy potential of fruit tree pruned biomass in Croatia.Spanish Journal of Agricultural Research, (2),292-298

61. Huber GW, Iborra S, Corma A (2006) Synthesis of transportation fuels from biomass: chemistry, catalysts, and engineering. Chem Rev 106(9):4044-4098

62. Vassilev SV, Baxter D, Andersen LK, Vassileva CG (2010) An overview of the chemical composition of biomass. Fuel 89(5):913-933

63. Senelwa K, Sims RE (1999) Fuel characteristics of short rotation forest biomass. Biomass Bioenergy 17(2):127-140

64. Aho M, Gil A, Taipale R, Vainikka P, Vesala H (2008) A pilot-scale fireside deposit study of co-firing Cynara with two coals in a fluidised bed. Fuel 87(1):58-69

65. Obernberger I, Brunner T, Bärnthaler G (2006) Chemical properties of solid biofuels-significance and impact. Biomass Bioenergy 30(11):973-982

66. Obernberger I, Biedermann F, Widmann W, Riedl R (1997) Concentrations of inorganic elements in biomass fuels and recovery in the different ash fractions. Biomass Bioenergy 12(3):211-224

67. McKendry P (2002) Energy production from biomass (part 3): gasification technologies. Bioresour Technol 83(1):55-63

68. Arshadi M, Gref R, Geladi P, Dahlqvist SA, Lestander T (2008) The influence of raw material characteristics on the industrial pelletizing process and pellet quality. Fuel Process Technol 89(12):1442-1447

Page $11 / 15$ 
69. Wichianphong N, Maison W (2020) Preparation of biofuel pellets from water hyacinth and waste coffee grounds. RMUTSB ACADEMIC JOURNAL 8(2):140-152

70. Han Y, Tahmasebi A, Yu J, Li X, Meesri C (2013) An Experimental Study on Binderless Briquetting of Low-Rank Coals. Chem Eng Technol 36(5):749-756

71. Arulprakasajothi M, Beemkumar N, Parthipan J, raju Battu N (2020) Investigating the physio-chemical properties of densified biomass pellet fuels from fruit and vegetable market waste. Arabian Journal for Science and Engineering 45(2):563-574

\section{Figures}

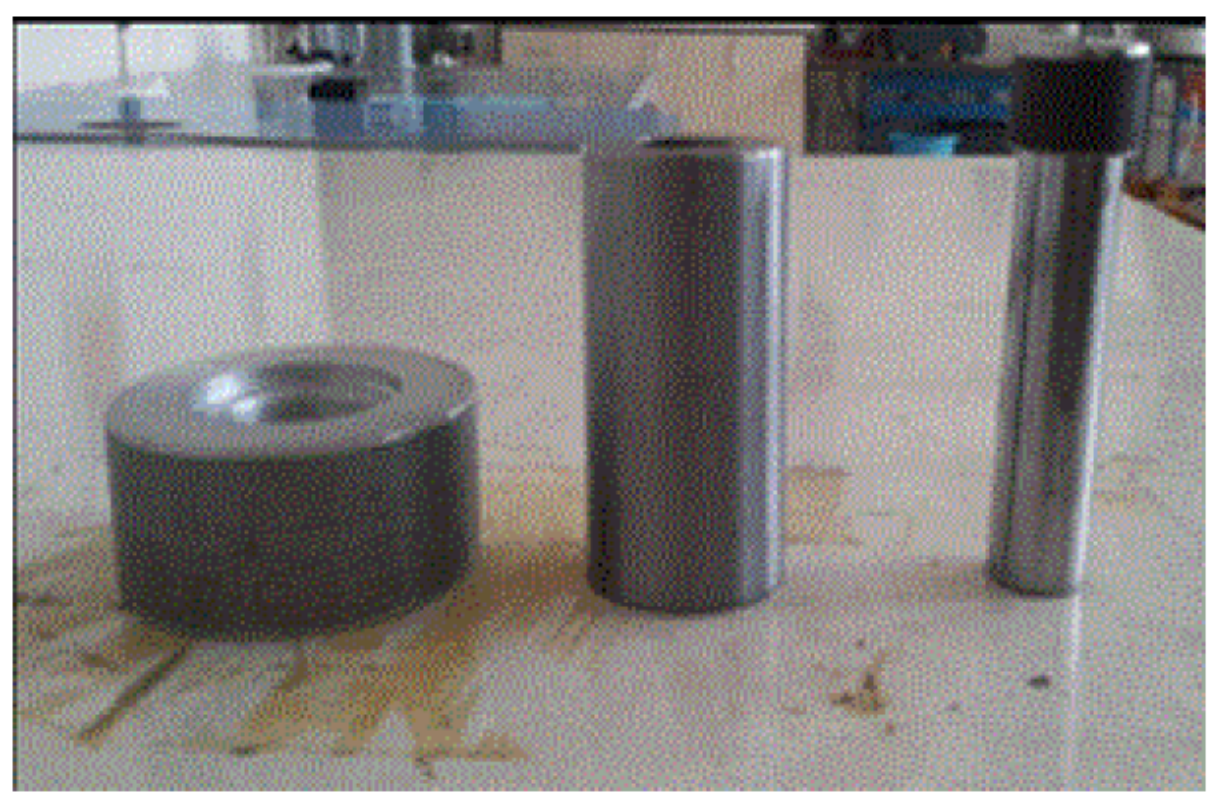

\section{Figure 1}

Custom design cylindrical pellet die 


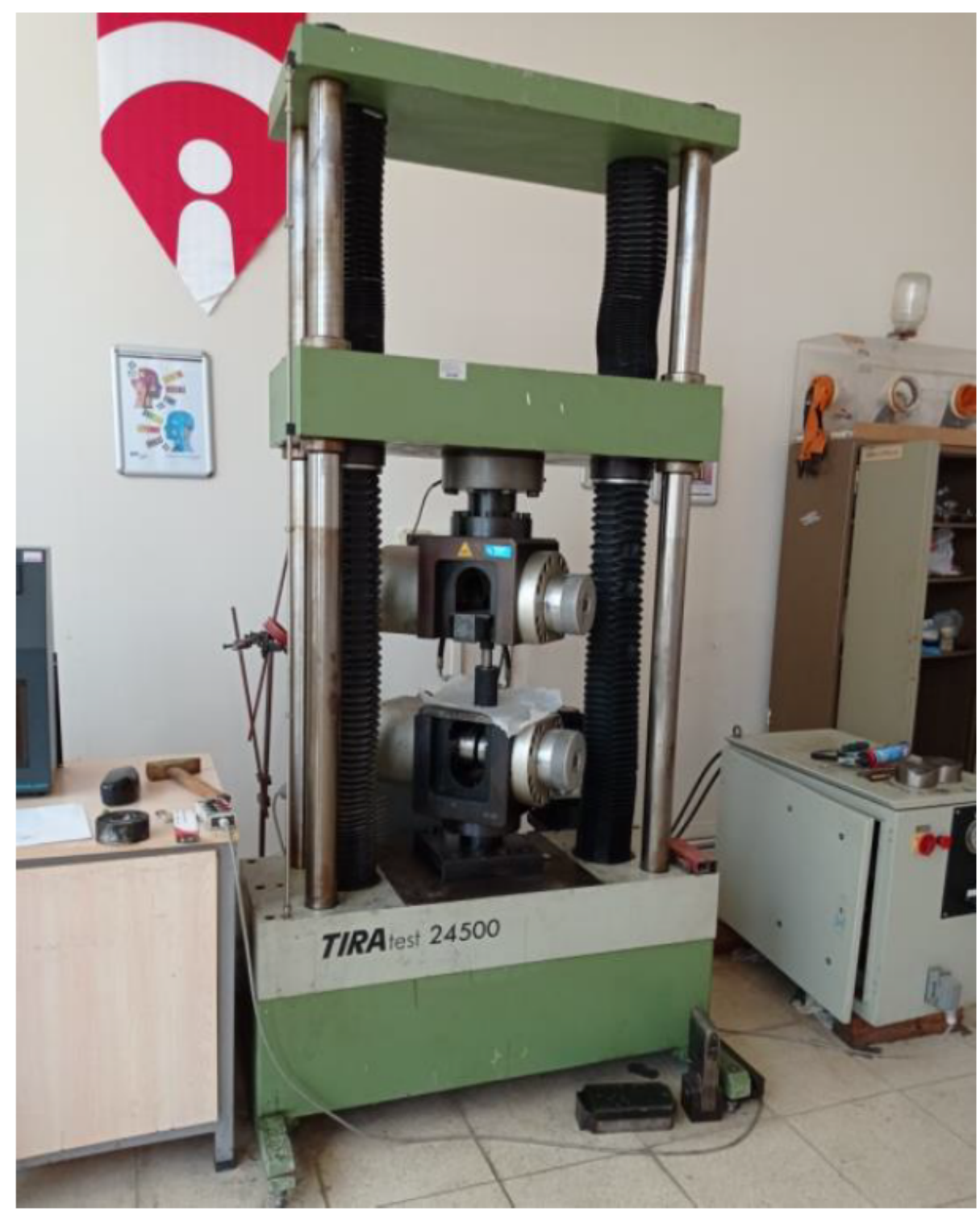

Figure 2

Pressing table 


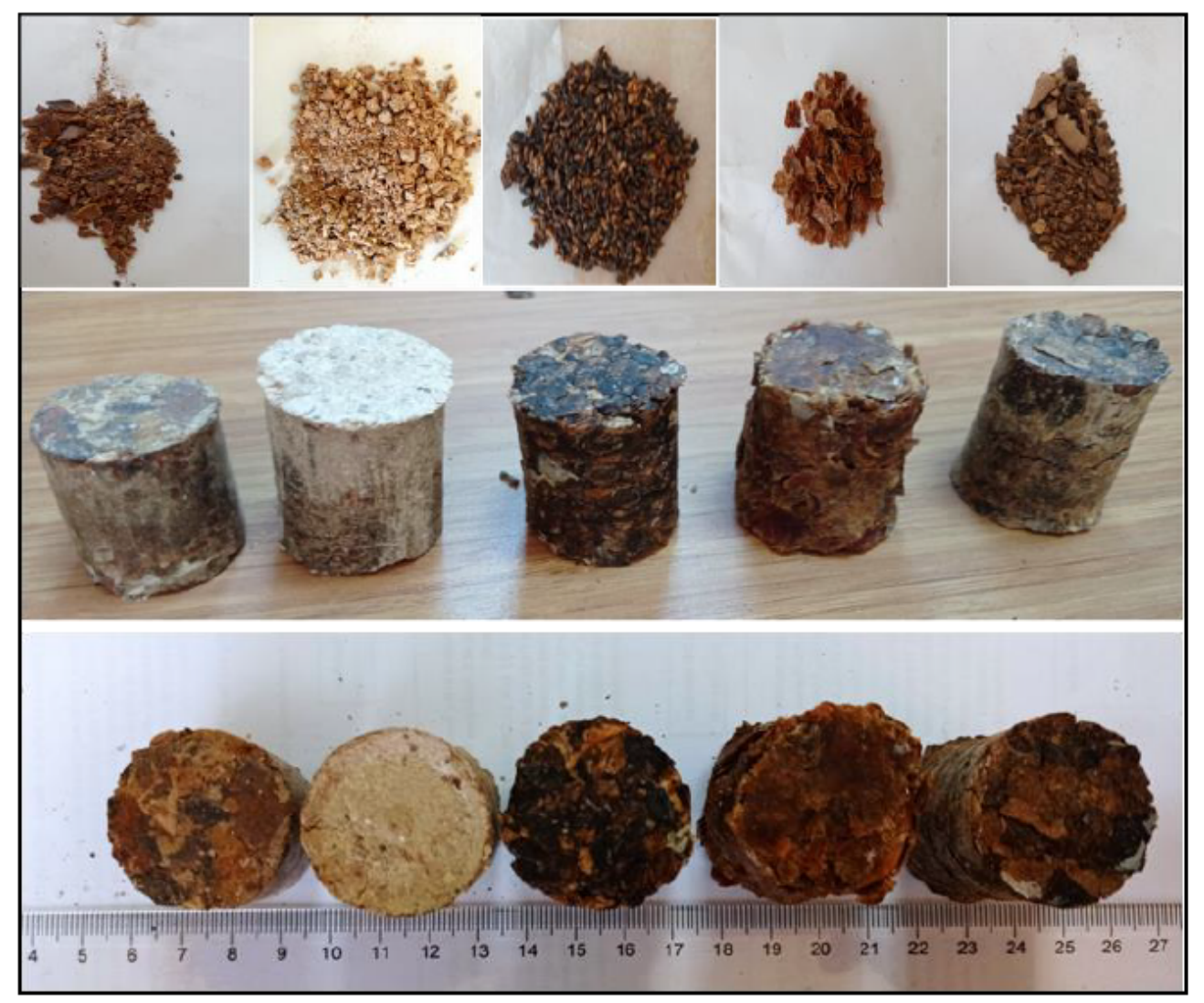

Figure 3

Experimental pellet samples

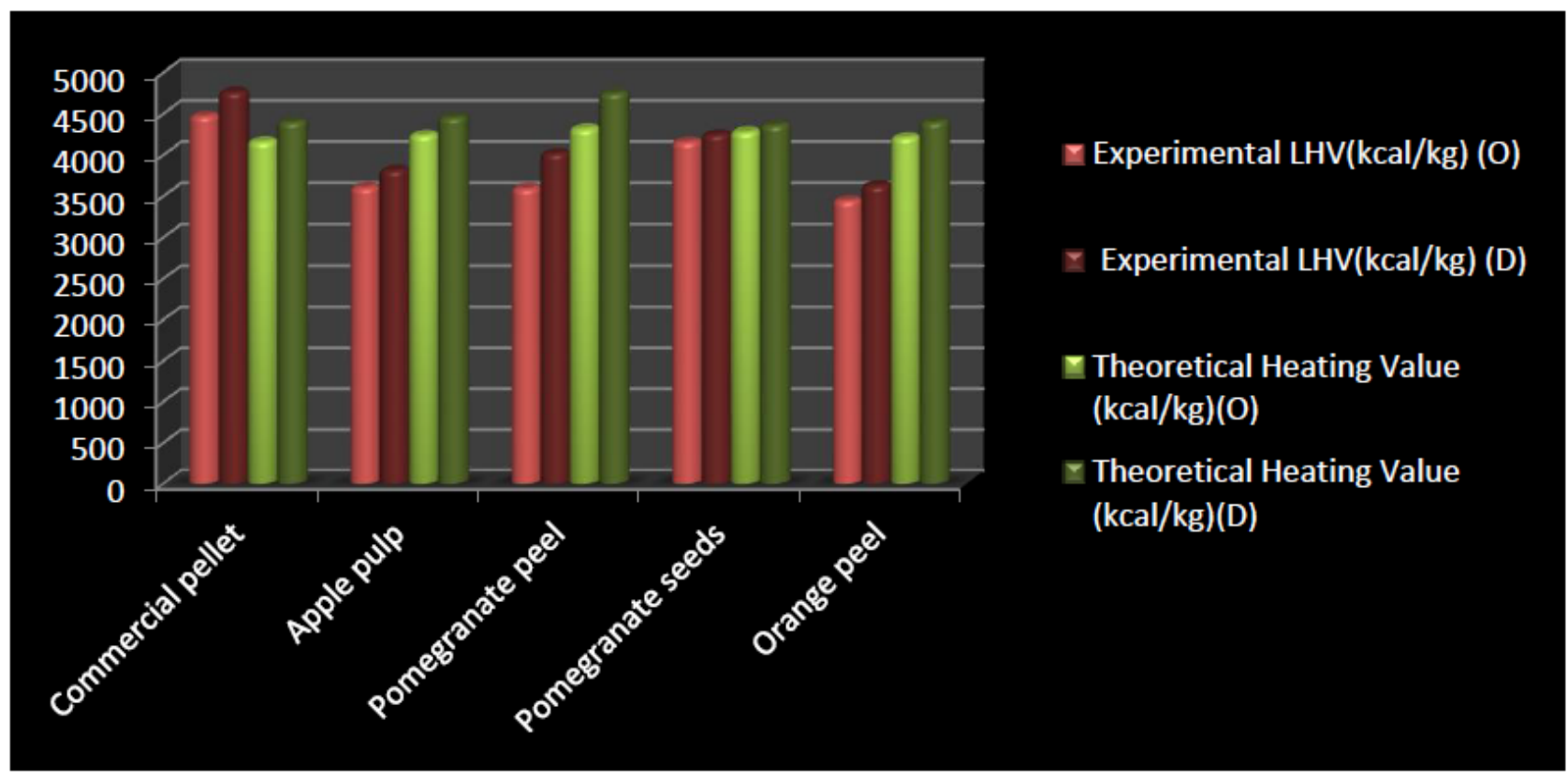

Figure 4

Experimental and theoretical LHV results of test samples (O: Original, D: Dry) 


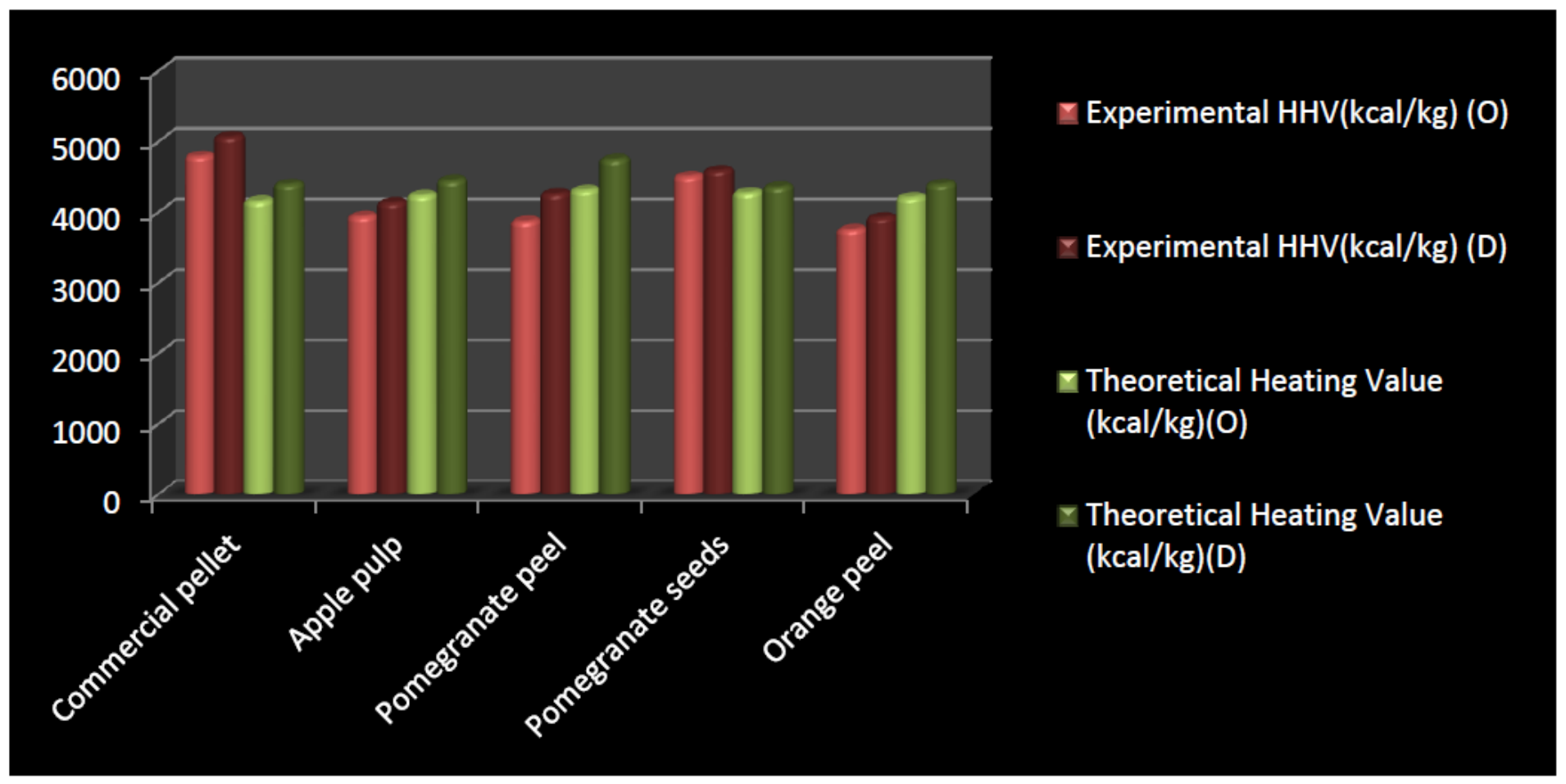

Figure 5

Experimental and theoretical HHV results of test samples (O: Original, D: Dry) 